\title{
Atención Odontológica en Pandemia: Consideraciones para su Reanudación
}

\author{
Considerations for Resuming Dental Treatment in a Pandemic Context
}

\author{
Lidia Bravo R. ${ }^{1,2}$ \& Denisse Lagos Tissie ${ }^{1}$
}

BRAVO, R. L. \& LAGOS, T. D. Atención odontológica en pandemia: Consideraciones para su reanudación. Int. J. Odontostomat., 14(4):464-465, 2020.

Sr. Editor,

En el contexto de la pandemia mundial de COVID-19 que también afecta a nuestro país, vivimos el mes pasado la suspensión temporal de la garantía de oportunidad para las patologías GES, incluyendo las odontológicas, quedando salvaguardada solamente, por indicación Ministerial, la Garantía № 46, Urgencia Odontológica Ambulatoria, asegurando el acceso a la atención odontológica de urgencias y cuadros clínicos que pudieran agudizarse en el corto plazo (MINSAL , 2020).

Hace unos días, el Sr. Ministro de Salud informó en conferencia de prensa que a partir de esta semana las garantías GES deberán ser cumplidas y que "no hay prohibición de consultas ambulatorias". Esta situación, aplicada al ámbito odontológico, tiene graves implicancias para la salud de la población y del personal de salud.

Es bien sabido que, debido a las características propias de la atención odontológica (estrecha cercanía entre profesional y paciente, uso de gran cantidad de instrumental y constante generación de aerosoles), los odontólogos y su personal de apoyo son el personal sanitario más expuesto a contagio del virus SARS-CoV-2. De hecho, ha sido el mismo Ministerio de Salud el que ha establecido recomendaciones para la atención odontológica en el contexto de Fase IV de la pandemia, diferenciando equipo de protección personal (EPP) para procedimientos con y sin generación de aerosoles en pacientes sospechosos y confirmados, recomendando diferir las atenciones electivas, e implementando estrategias de seguimiento remoto de pacientes (vía telefónica, por ejemplo) (MINSAL).

La vigencia plena de los Ges Odontológicos implica que las usuarias embarazadas, los usuarios de 6 y 60 años, estos últimos población especialmente vulnerable al virus, deberán acudir a sus prestadores de salud para poder exigir su derecho a la atención garantizada antes de que se venzan, a pesar de los constantes llamados de la autoridad a quedarse en casa. Esta situación, que coincide con la fecha en que las mismas autoridades de salud han previsto el peak de contagios por covid-19, aumenta por sí misma la exposición de la población al virus, pero es aún más preocupante por el hecho de que la población adulta chilena tiene un severo daño oral, por lo que atender a embarazadas y población de 60 años implicará, sin lugar a dudas, la generación de aerosoles y, por tanto, aumento del uso de EPP especiales para no acrecentar aún más el riesgo de contagio para el profesional, su personal de asistencia y el usuario. Reestablecer todas las atenciones ambulatorias podría presentar un panorama aún más desolador.

A casi dos meses desde la detección del primer caso de covid-19 en Chile, los profesionales de la salud nos hemos enfrentado a un cambio en la orientación ética de las atenciones sanitarias, ante la necesidad de limitar las atenciones electivas de salud y priorizar medidas sanitarias en protección de

\footnotetext{
${ }^{1}$ Cirujano Dentista, Especialista en Odontología Legal y Forense, Chile.

${ }^{2}$ Laboratorio de Pericias en Odontología Forense (LPO), Facultad de Odontología, Universidad de La Frontera, Temuco, Chile.
} 
la salud pública (Dunham et al., 2020). Esta mirada nos obliga a proyectar el retorno a las atenciones odontológicas ambulatorias regulares, incluidos los GES, una vez que se haya realizado el análisis y adecuación de los protocolos en cuanto a las medidas de protección que deberán implementarse para proteger tanto al usuario como al equipo dental, sin olvidar, por supuesto, la factibilidad de adquirir los EPP adicionales necesarios y los costos económicos que esto implica. Conjuntamente, deberá realizarse el ajuste del rendimiento estimado de los odontólogos, tanto para poder contar con el tiempo suficiente para desinfectar el box entre pacientes, como para evitar aglomeraciones en la sala de espera.

El retorno seguro a las atenciones dentales pasará imperiosamente por un cambio en la manera en que se brindan hoy estas atenciones, y significará, sin duda, una mejora en beneficio de la población usuaria.

\section{REFERENCIAS BIBLIOGRÁFICAS}

Ministerior de Salud (MINSAL). Orientaciones para atención odontológica en Fase IV COVID-19. Santiago de Chile, Subsecretaría de Salud Pública. División de Prevención y Control de Enfermedades. Departamento Salud Bucal. Ministerio de Salud, Gobierno de Chile, 2020. Disponible en https:// diprece.minsal.cl/wp-content/uploads/2020/03/ORIENTACIONES-ATENCION-ODONTOLOGICAS-COVID-19-.pdf

Dunham, A. M.; Rieder, T. N. \& Humbyrd, C. J. A. A Bioethical Perspective for Navigating Moral Dilemmas Amidst the COVID19 Pandemic. J. Am. Acad. Orthop. Surg. DOI: 10.5435/JAAOSD-20-00371

Dirección para correspondencia:

Lidia Bravo

Universidad de La Frontera

Temuco

CHILE

Email: lidia.bravo@ufrontera.cl

Recibido : 05-05-2020

Aceptado: 07-05-2020 